\title{
Violence, justice, and health: implications for a multisectoral collaboration
}

\author{
Bandy X. Lee ${ }^{1} \cdot$ Manuel P. Eisner ${ }^{2} \cdot$ Maya Prabhu $^{1} \cdot$ Charles C. Dike $^{1}$
}

Received: 20 September 2018 / Accepted: 26 September 2018/ Published online: 17 October 2018

(C) Swiss School of Public Health (SSPH+) 2018

Until recently, criminal justice has been the predominant way by which society has intervened in problematic human violence. Then, there has been the rise of a public health approach, which views human violence as an issue one can research, understand, and prevent. Mental health and the social sciences shed light on how psychological and social dimensions shape human violence. Laws, in turn, protect civil and human rights and set standards for governance. All these different domains have much to gain from collaborating with one another, but there has been insufficient exchange between them.

With the United Nations' 2030 Agenda for Sustainable Development (UN 2015) and its wide-ranging, cooperative goals for sustained security and peace, it is a propitious time to consider how criminal justice and public health, as well as their allied fields, can join forces. Violence is a complex, human construct that cannot be understood outside of social, cultural, political, religious, and structural contexts. Therefore, any endeavor to prevent violence and promote peace requires broad collaboration and sustained commitment to these goals. The World Health Organization (WHO) Violence Prevention Alliance (VPA) continues in its diverse work to build bridges.

At first sight, the emphasis on healing in public health and punishment in criminal justice makes such a dialogue seem difficult. However, there are more commonalities than we often recognize. Increasingly, it is understood that the core mission of the police in democratic societies is to reduce crime and violence by using the best evidence on

This editorial is part of the special issue "Violence, Justice, and Health: Implications for a Multisectoral Collaboration".

Bandy X. Lee

bandy.lee@yale.edu

1 Law and Psychiatry Division, Yale University, 34 Park Street, New Haven, CT 06519, USA

2 Institute of Criminology, University of Cambridge, Cambridge, UK how to achieve these goals. Public health methodologies provide the detailed epidemiological data and experiments to advise criminal justice policy. Often, close cooperation between criminal justice and public health agencies is essential to achieve violence reduction goals. On the other hand, public health approaches to violence prevention require a functioning law enforcement system, thoughtful implementation of laws, and robust mental health services for victims and potential perpetrators.

High-quality interdisciplinary research can help to strengthen effective collaboration between the public health and criminal justice systems. For example, research on the mental health interventions that can prevent future perpetration of violence can help to reduce costly imprisonment as well as societal harm (Gilligan and Lee 2004). Similarly, evaluation research on the effectiveness of collaborative service delivery between police, social welfare, mental health, and public health actors in cases of child maltreatment or victims of intimate partner violence can show how different sectors can work together more effectively.

Contributions to this issue make important steps toward such an integrated view, incorporating studies from a range of geographic regions and income levels, as in past issues (Lee et al. 2014). First, we offer an example of an innovative, integrative approach to criminal justice, mental health, and family support in Connecticut, USA, by Lee and colleagues. Then, we present a study spanning 28 European countries, in which Sanz-Barbero and colleagues show empirical evidence on how macrosocial policies related to gender equality may help to reduce intimate partner violence.

Continuing with the theme of gender violence, De and Murshid highlight how cultural beliefs that justify intimate partner violence affect the extent to which victimization experiences are associated with a higher likelihood screen for depression in Bangladesh. Djikanovic and colleagues reveal that promoting gender equality is important to address beliefs related to wife beating in a young minority 
population in Serbia. Similarly, Silva and Roncalli demonstrate through a cross-sectional analysis of Brazil, that strategies to reduce individual risk factors must be integrated with broader social policies. Wathen and colleagues show that integrating services from health to criminal justice especially help marginalized gender and sexual minorities in Canada.

Moving onto urban violence, Peres and colleagues present, through a multilevel study in Brazil, the significance of ecological factors in school-age youth violence. Worrall and Kjaerulf examine, through a study in Kenya, ways to overcome the tensions between Law Enforcement and Civil Society to Prevent Urban Violence. In a similar vein, Bowman and colleagues demonstrate how data sharing across sectors can be advance violence prevention in the context of South Africa. Ward and colleagues examine the effectiveness of community-based peace initiative that may significantly reduce murder rates.

Izadi and colleagues, through a study of suicide in Iran, assert the need for widespread health policy intervention and reduction of stigma. Cleveland and colleagues, through a study of the impact of immigration detention, expose the damage to mental health that symbolic violence and disempowerment pose. Lastly, Lee and colleagues emphasize the association between structural violence and violent behavior and the importance of studying political structures in violence research.

Taken as a whole, this special issue continues the efforts on the part of the WHO to bring coherence to our collective aim of reducing violence around the world. Recognizing the effectiveness of comprehensive, collaborative efforts, we hope to inch us toward understanding how to create a healthier, more peaceful world.

Acknowledgements The guest editors thank Christopher Mikton for his early conceptual input in the context of the VPA; Michael Norko, Tanuja Gandhi, Paul Bryant, Morkeh Blay-Tofey, and Marisol Orihuela for their author recommendations; Rachel Sitkin, Ilan BelkindGerson, Berit Kieselbach, and Grace Lee for their editorial help; and
Howard Zonana and Madelon Baranoski, whose pioneering work inspired this special issue. Finally, special acknowledgment goes to Anke Berger, Managing Editor of IJPH, who made this special issue possible.

\section{Compliance with ethical standards}

Conflict of interest All authors declare that they have no conflict of interest.

Ethical approval This article does not contain any studies with human participants performed by any of the authors.

Informed consent Not applicable.

\section{References}

Gilligan J, Lee BX (2004) Beyond the prison paradigm: from provoking violence to preventing it by creating 'anti-prisons' (residential colleges and therapeutic communities). Ann N Y Acad Sci 1036(1):300-324

Lee BX, Leckman JF, Mbwambo JKK (2014) Violence and health: current perspectives from the WHO Violence Prevention Alliance. Aggress Violent Behav 19(6):609-615

United Nations (2015) Transforming our world: the 2030 agenda for sustainable development. United Nations, New York. Retrievable at: http://www.un.org/ga/search/view_doc.asp?symbol=A/ 70/L.1 andLang=E. Accessed 27 July 2018

Bandy X. Lee, M.D., M.Div., is Assistant Clinical Professor in the Law and Psychiatry Division at Yale University School of Medicine and Director of the Violence and Health Study Group.

Manuel P. Eisner, Ph.D., is Professor of Comparative and Developmental Criminology at the University of Cambridge Institute of Criminology and Director of the Violence Research Centre.

Maya Prabhu, M.D., LL.B., is Assistant Professor in the Law and Psychiatry Division at Yale University School of Medicine.

Charles C. Dike, M.D., M.P.H., is Associate Professor in the Law and Psychiatry Division at Yale University School of Medicine. 